ISSN: 2146-3042

DOI: $10.25095 /$ mufad.852162

\title{
Döviz Piyasalarının Davranışlarını Açıklamada Etkin Piyasalar Hipotezi ile Adaptif Piyasalar Hipotezinin Karşılaştırılması: BRICS-T Ülkeleri Üzerine Ampirik Bir Çalışma*
}

Oktay ÖZKAN**

\section{ÖZET}

Bu çalışmanın amacı Brezilya, Rusya, Hindistan, Çin, Güney Afrika ve Türkiye döviz piyasalarının davranışlarını açılklamada Etkin Piyasalar Hipotezi ile Adaptif Piyasalar Hipotezi'ni karşılaştırmaktır. İlgili ülkelerin yerel para birimlerinin Dolar cinsi değerlerinin 17.07.2005-09.02.2020 tarihleri arasındaki haftalık getiri oranları üzerinde, sabit uzunluklu haraketli kayan pencereler yöntemi kullanılarak getiri oranı tahmin edilebilirliği için Dominguez ve Lobato (2003) tarafindan geliştirilmiş olan Dominguez-Lobato testi ile analizler gerçekleştirilmiştir. Analizler sonucunda BRICS-T döviz piyasalarının zayıf formdaki etkinliğinin zaman içerisinde değişim gösterdiği ve BRICS-T döviz piyasalarının davranışlarını açıklamada Adaptif Piyasalar Hipotezi'nin Etkin Piyasalar Hipotezi’ne göre daha başarılı olduğu belirlenmiştir. Tarihsel fiyat bilgileri kullanılarak getiri oranı tahmininde CNY/USD ve INR/USD kuru için diğer kurlara göre daha başarılı sonuçlar elde edilebileceği, BRL/USD ve ZAR/USD kurlarının getiri oranlarının tahmininde ise başarı şansının oldukça düşük olduğu ulaşılan diğer önemli sonuçlardır. Genel olarak bakıldığında Brezilya ve Güney Afrika döviz piyasalarının diğer BIRCS-T ülke döviz piyasalarına göre daha fazla zaylf formda etkin olduğu söylenebilir.

Anahtar Kelimeler: Döviz piyasaları, adaptif piyasalar hipotezi, etkin piyasalar hipotezi, getiri oranı tahmin edilebilirliği.

JEL Sinıflandırması: C22, G11, G14, F31.

Comparison of Efficient Markets Hypothesis and Adaptive Markets Hypothesis in Explaining the Behavior of Foreign Exchange Markets: An Empirical Study on BRICS-T Countries

\section{ABSTRACT}

The purpose of this study is to compare the Efficient Markets Hypothesis and Adaptive Markets Hypothesis to explain the behavior of BRICS-T foreign exchange markets. Analyses were carried out using the Dominguez-Lobato test developed by Dominguez and Lobato (2003) for the return rate predictability using the fixed-length rolling windows method on the weekly rate of return of the Dollar values of the local currencies of the relevant countries between 17.07.2005-09.02.2020. As a result of the analyses, it was determined that the efficiency of BRICS-T foreign exchange markets in the weak form changed over time and Adaptive Markets Hypothesis was more successful than Efficient Markets Hypothesis in explaining the behavior of BRICS-T foreign exchange markets. It was another important result that CNY/USD and INR/USD exchange rates can be more successful than other currencies in the rate of return estimation using historical price information, and the chance of success is quite low in the rate of return estimation of BRL/USD and ZAR/USD exchange rates. In general, it can be said that the Brazilian and South African foreign exchange markets are more efficient in weak form than other BIRCS-T countries.

Keywords: Foreign exchange markets, adaptive markets hypothesis, efficient markets hypothesis, return rate predictability.

Jel Classification: C22, G11, G14, F31.

\footnotetext{
* Makale Gönderim Tarihi: 17.02. 2020, Makale kabul tarihi: 06.04.2020, Makale Türü: Nicel Araştırma ** Arş. Gör. Dr., Tokat Gaziosmanpaşa Üniversitesi İ.İ.B.F. İşletme Bölümü, oktay.ozkan@gop.edu.tr, ORCID: 0000-0001-9419-8115.
} 


\section{GíRiş}

Ekonomi ve finans alanındaki en eski ve kalıcılığını günümüzde de koruyan sorulardan bir tanesi, finansal varlık fiyatlarının geçmiş fiyatlar kullanılarak tahmin edilip edilemediğidir. Samuelson (1965) ve Fama $(1965,1970)$ tarafindan geliştirilen Etkin Piyasalar Hipotezi'ne göre varlık fiyatları mevcut ve ilgili bütün bilgileri tam ve anlık olarak yansıtmaktadır. Piyasalarda bulunan aktörlerin rasyonel olduğu varsayımı üzerine inşa edilen Etkin Piyasalar Hipotezi’ne göre, piyasalara gelen bilgiler çok hızlı bir şekilde yayılmakta ve gecikmesiz bir şekilde rasyonel aktörler tarafından varlık fiyatlarına yansıtılmaktadır (Malkiel, 2003: 59). Hipoteze göre varlık fiyatları mevcut bütün bilgileri yansıttığından herhangi bir tarihsel bilgi kullanılarak finansal varlıkların gelecekteki değerleri tahmin edilememektedir. Varlık fiyatları piyasalara gelen bilgilerin içeriğine göre rassal bir şekilde oluşmaktadır (Karadağlı ve Omay, 2012: 235; Korkmaz vd., 2010: 1139). Finansal varlık fiyatlarının tarihsel bütün fiyat bilgilerini içerdiğini belirten zayıf form piyasa etkinliğine göre, zayıf formda etkin olan piyasalarda varlıkların geçmiş fiyat hareketleri kullanılarak gelecekteki fiyatları/getiri oranları tahmin edilememektedir (Kulalı, 2016: 48). Bu nedenle varlıkların getiri oranlarının tahmin edilebilirlik durumları analiz edilerek, piyasaların zayıf formda etkin olup olmadıkları belirlenebilmektedir (Charles vd., 2012: 1608).

Döviz piyasalarında kur fiyatlarının (getiri oranlarının) tahmin edilebilir olmasının diğer bir ifadeyle döviz piyasalarında zayıf formda etkinlikten sapmaların nedenleri olarak: (1) Sermayenin fiyatlandırılması ve riskin değerlenmesindeki bozulmalar nedeniyle döviz kurlarının denge düzeyinde belirlenmemesi (Smith vd., 2002); (2) döviz kurlarının piyasa yeni gelen bilgilere hızlı uyum sağlayamaması (Fama, 1970; Melvin, 2004); (3) döviz kuru kontrollerinin mevcudiyeti ve buna bağlı olarak denge kuru ile resmi kur arasında farklılık olması nedeniyle paralel/karaborsa oluşumu (Diamandis vd., 2007); (4) döviz kuru rejimi ve düzenleyici değişikliklerin, yabancı bankaların döviz piyasalarına ve ürünlerine erişimlerini kısıtlaması; (5) döviz kurlarındaki ani yükselme ve ani düşüş olayları (Liu ve He, 1991); (6) merkez bankası müdahaleleri (Dominguez ve Frankel, 1993; Yilmaz, 2003; Beine vd., 2009) görülmektedir. Etkin Piyasalar Hipotezi'ne göre piyasalar ya etkindir ya da etkin değildir. Lo, Etkin Piyasalar Hipotezi’nin gerçek piyasaların davranışlarını açıklamadaki eksikliklerini gidermek amacıyla 2004 yılında Adaptif Piyasalar Hipotezi'ni geliştirmiştir. Adaptif Piyasalar Hipotezi'ne göre bireyler ne tamamen rasyoneldirler ne de tamamen irrasyoneldirler; ekonomik yeniliklere uyum sağlayan akı1lı, ileriye dönük ve rekabetçidirler. Adaptif Piyasalar Hipotezi piyasaların Etkin Piyasalar Hipotezi'nin belirttiği üzere durağan değil dinamik olduğunu ifade etmektedir. Hipoteze göre varlık fiyatların (getiri oranların) tahmin edilebilirliği, diğer bir ifadeyle zayıf formdaki piyasa etkinliği süreklilik arz eden bir olgu değil, zaman içerisinde değişim göstermektedir (Lo, 2004: 25; 2005: 31; 2012: 24).

$\mathrm{Bu}$ çalışmanın amacı döviz piyasalarının davranışlarını açıklamada Etkin Piyasalar Hipotezi ile Adaptif Piyasalar Hipotezi'ni karşılaştırmaktır. Bu amaç çerçevesi içerisinde 17.07.2005-09.02.2020 tarihleri arasındaki Brezilya, Rusya, Hindistan, Çin, Güney Afrika ve Türkiye (BRICS-T) ülkelerine ait para birimlerinin (Brezilya Reali (BRL), Rus Rublesi (RUB), Hindistan Rupisi (INR), Çin Yuanı (CNY), Güney Afrika Randı (ZAR) ve Türk Lirası (TRY)) Dolar (USD) karşısındaki fiyatlarına ait haftalık getiri oranları kullanılarak getiri oranı tahmin edilebilirliği için geliştirilen ve normal dağılmayan aynı zamanda değişen varyans özelliği gösteren veri setlerinde oldukça başarılı sonuçlar gösteren Dominguez ve Lobato (2003) tarafindan geliştirilmiş olan Dominguez-Lobato (DL) testi ile analizler 
gerçekleştirilecek ve elde edilen bulgular yorumlanacaktır. Bu çalışmanın, BRICS-T döviz piyasalarının zayıf formdaki piyasa etkinliğini hangi hipotezin daha iyi açıkladığını göstermesi, piyasaları zayıf formdaki etkinlik düzeylerine göre karşılaştırması ve hangi döviz kuru için tarihsel fiyat hareketlerinden faydalanılabileceğini göstermesi bakımından literatüre önemli katkılar sağlayacağı düşünülmektedir. Çalışmanın diğer bölümlerinde sırasıyla literatür taraması, metodoloji ve veri seti, ampirik bulgular ve son olarak sonuç ile ilgili bilgiler yer almaktadır.

\section{LITERATÜR TARAMASI}

Çalışmanın bu kısmında BRICS-T ülke döviz piyasalarının zayıf formdaki etkinliği kapsamında gerçekleştirilen çalışmalar ile ilgili bilgiler yer almaktadır. Söz konusu çalışmalar aşağıdaki gibidir:

Aron ve Ayogu (1997) çalışmalarında Güney Afrika döviz piyasasının zayıf formdaki etkinlik durumunu analiz etmişlerdir. Şubat 1979-Mart 1995 dönemleri arasında eşbütünleşme yöntemi ile analizler gerçekleştirmişlerdir. Analizler sonucunda Güney Afrika döviz piyasasının zayıf formda etkin olmayan bir piyasa olduğunu vurgulamışlardır.

Ertekin (2003) çalışmasında Türk döviz piyasasının zayıf formdaki etkinliğini incelemiştir. Ocak 1995-Mayıs 2003 dönemleri arasındaki verileri kullanarak Run ve Ki-kare testi ile serisel korelasyon yöntemini kullanarak analizler gerçekleştirmiştir. Analizler sonucunda Türk döviz piyasasının zayıf formda etkin bir piyasa olmadığını belirtmiştir.

Oh vd. (2007) çalışmalarında 17 ülke döviz piyasasının zayıf formdaki etkinliğini incelemişlerdir. 1984-2004 yılları arasındaki verileri kullanarak yaklaşık entropi (ApEn) yöntemi ile analizler gerçekleştirmişlerdir. Analizler sonucunda Güney Afrika döviz piyasasının Hindistan ve Çin döviz piyasalarına göre daha fazla zayıf formda etkin olduğu sonucuna ulaşmışlardır.

Berke vd. (2014) çalışmalarında Türk döviz piyasasının zayıf formdaki etkinlik durumunu araştırmışlardır. Nisan 2006-Aralık 2013 dönemleri arasındaki verileri kullanarak yapısal kırılmalı birim kök ve eşbütünleşme yöntemleri ile analizler gerçekleştirmişler ve Türk döviz piyasasının zayıf formda etkin bir piyasa olduğu sonucuna ulaşmışlardır.

Çiçek (2014) çalışmasında Türk döviz piyasasının zayıf formdaki etkinliğini analiz etmiştir. Şubat 2005-Temmuz 2013 dönemleri arasındaki verileri kullanarak Augmented Dickey-Fuller ve Phillips-Perron birim kök testleri ile analizler gerçekleştirmiştir. Analizler sonucunda Türk döviz piyasasının zayıf formda etkin bir piyasa olduğunu vurgulamıştır.

Mohamed ve Banu (2015) çalışmalarında Hindistan döviz piyasasının zayıf formdaki etkinliğini araştırmışlardır. Ocak 2000-Ekim 2013 dönemleri arasındaki verileri kullanarak birim kök testleri ile analizler gerçekleştirmişler ve Hindistan döviz piyasasının zayıf formda etkin bir piyasa olduğu sonucuna ulaşmışlardır.

Kumar ve Kamaiah (2016) çalışmalarında BRICS döviz piyasalarının zayıf formdaki etkinliğini incelemişlerdir. Nisan 1994-Eylül 2014 tarihleri arasındaki veri setlerini kullanarak 
gerçekleştirmiş oldukları varyans rasyo testi sonucunda BRICS döviz piyasalarının zayıf formda etkin olmadığını belirtmişlerdir.

Palma ve Sartoris (2016) çalışmalarında Brezilya döviz piyasasının zayıf formdaki etkinliğini araştırmışlardır. 1999 ile 2013 yılları arasındaki verileri kullanarak yapay sinir ağı modeli ile analizler gerçekleştirmişlerdir. Analizler sonucunda Brezilya döviz piyasasının zayıf formda etkin bir piyasa olmadığını vurgulamıştır.

Khuntia ve Pattanayak (2017) çalışmalarında Hindistan döviz piyasasının zayıf formdaki etkinliğini analiz etmişlerdir. Ocak 1999-Aralık 2015 dönemleri arasındaki verileri kullanarak doğrusal ve doğrusal olmayan yöntemlerle analizler gerçekleştirmişlerdir. Analizler sonucunda Hindistan döviz piyasasının zayıf form etkinliğinin Adaptif Piyasalar Hipotezi'ne uyumlu bir şekilde zaman içerisinde değişim gösterdiğini belirtmişlerdir. Kumar (2018) çalışmasında Hindistan yerel para biriminin Dolar karşısındaki değerine ait Ocak 1999-Kasım 2017 dönemleri arasındaki günlük verilerini kullanarak Otomatik Varyans Oranı ve Belaire-Franch ve Contreras (2004) Sıra-Tabanlı testleri ile gerçekleştirmiş olduğu analizler neticesinde Hindistan döviz piyasası için benzer sonuçlar elde etmiştir.

Mukherjee (2018) çalışmasında BRICS döviz piyasalarının zayıf formdaki etkinliğini analiz etmiştir. 31 Mart 2004-30 Nisan 2018 tarihleri arasındaki verileri kullanarak OLS, VAR, VECM ve Johansen eşbütünleşme testi ile analizler gerçekleştirmiş ve BRICS döviz piyasalarının zayıf formda etkin piyasalar olmadığı sonucuna ulaşmıştır.

Özdemir vd. (2018) çalışmalarında Türkiye döviz piyasasının zayıf formdaki etkinliğini araştırmışlardır. 02.01.2006-30.05.2018 tarihleri arasındaki verileri kullanarak ARFIMA-FIGARCH modelleri ile analizler gerçekleştirmişlerdir. Analizler sonucunda Türk Döviz piyasasının zayıf formda etkin piyasa olmadığını vurgulamışlardır.

Gupta ve Plakandaras (2019) çalışmalarında BRICS ve İngiltere döviz piyasalarının zayıf formdaki etkinliğini incelemişlerdir. Her bir döviz piyasası için farklı tarih aralığındaki aylık veri setlerini kullanarak quantilogram yöntemiyle analizler gerçekleştirmişler ve BRICS ve İngiltere döviz piyasalarının zayıf formdaki etkinliğinin Adaptif Piyasalar Hipotezi'ni desteklediğini belirtmişlerdir.

Yukarıda yer alan çalışmalar bazı BRICS-T ülkelerine ait döviz piyasaları üzerinde Etkin Piyasalar Hipotezi veya Adaptif Piyasalar Hipotezi'nin geçerliliğini değerlendirmişlerdir. Literatürde BRICS-T döviz piyasalarını zayıf form etkinlik kapsamında karşılaştıran ya da hangi BRICS-T döviz kuru için tarihsel fiyat hareketlerinden faydalanılabileceğini gösteren herhangi bir çalışmaya rastlanılmamıştır. Bu çalışma BRICS-T döviz piyasalarının zayıf formdaki piyasa etkinliğini hangi hipotezin daha iyi açıkladığını göstermesi, piyasaları zayıf formdaki etkinlik düzeylerine göre karşılaştırması ve hangi döviz kuru için tarihsel fiyat hareketlerinden faydalanılabileceğini göstermesi bakımından yukarıda yer alan çalışmalardan farklılaşmaktadır.

\section{METODOLOJI VE VERİ SETİ}

$\mathrm{Bu}$ çalışmada BRICS-T döviz piyasalarının zayıf formdaki etkinliğini değerlendirebilmek için Dominguez ve Lobato (2003) tarafindan geliştirilmiş olan 
Dominguez-Lobato testi uygulanmıştır. DL testi, zaman serisi verilerinde doğrusal olmayan bağımlılıkların varlığını tespit etmek için tasarlanmış bir testdir (Khuntia ve Pattanayak, 2018: 27). Charles vd. (2011) çalışmalarında DL testinin doğrusal olmayan bağımlılık altında alternatif testlere göre daha iyi bir performans sergilediğini ve diğer testlerden daha fazla ampirik güce sahip olduğunu belirtmişler ve DL testinin, normal dağılmayan ve aynı zamanda koşullu değişen varyansa (heteroskedasticity) sahip zaman serisi veri setleri için oldukça iyi performans gösterdiğini vurgulamışlardır. Dominguez ve Lobato (2003) gösterge ağırlıklandırma fonksiyonunu dikkate alan ve Cramer-von Mises (CvM) ve KolmogorovSmirnov (KS) istatistiklerine dayalı DL testini geliştirmiştir. DL testinin matematiksel gösterimi denklem 1 ve 2'deki gibidir:

$$
\begin{gathered}
C v M_{T, p}=\frac{1}{\hat{\sigma}^{3} T^{2}} \sum_{j=1}^{T}\left[\sum_{t=1}^{T}\left(Y_{t}-\bar{Y}\right) 1\left(\tilde{Y}_{t, p} \leq \tilde{Y}_{j p p}\right)\right]^{2} \\
K S_{T, p}=\max _{1<i<T}\left|\frac{1}{\partial \sqrt{T} T} \sum_{t=1}^{T}\left(Y_{t}-\bar{Y}\right) 1\left(\tilde{Y}_{t, p} \leq \tilde{Y}_{j, p}\right)\right|
\end{gathered}
$$

(1) ve (2) numaralı denklemlerde yer alan $\tilde{Y}_{t, p}=\left(Y_{t-1}, \ldots, Y_{t-p}\right)$ gösterge işlevini, $p$ ise pozitif bir tamsayı1 ifade etmektedir (Charles vd., 2011: 152). DL testinin sonlu örneklemlerde uygulanabilmesi için Dominguez ve Lobato (2003) bootstrap kullanılması gerektiğini belirtmişlerdir. Bu çalışmada bootstrap değeri olarak Charles vd. (2017) tarafından önerilen değer olan 500 kullanılmıştır.

$\mathrm{Bu}$ çalışmada 10.07.2005-09.02.2020 tarihleri arasındaki BRICS-T ülke para birimlerinin USD karşısındaki haftalık kapanış fiyatları kullanılmıştır. Söz konusu haftalık veriler "Investing" isimli internet sitesinin veri tabanından temin edilmiştir (Erişim Tarihi: 14.02.2020). Verilerin başlangıç tarihi çalışma kapsamındaki örneklemler için ulaşılabilen en eski ve ortak olan tarih şeklinde belirlenmiştir. Örneklem seçiminde ise Türkiye'nin de içerisinde yer aldığı ve literatürde sıklıkla kullanılan BRICS-T ülke gruplandırması tercih edilmiştir. Seriler arasındaki boyut farkını düzeltmek için haftalık kapanış fiyatları veri setlerinin doğal logaritması alınmıştır. (Li vd., 2016: 679). Şekil 1 ve Tablo 1 'de yer alan bilgiler döviz kurları haftalık kapanış fiyatlarının durağan olmadığını belirttiğinden verilerin durağanlığının sağlanması için birinci farkları alınmıştır. Birinci farkları yakınsama probleminden kaçınmak için 100 ile çarpılarak haftalık getiri oranları hesaplanmıştır. Döviz kurlarının haftalık logaritmik kapanış fiyatları ve haftalık getiri oranlarına ait grafikler Şekil 1 'de yer almaktadır. 
BRL Kapanış Fiyatları

BRL Getiri Oranları
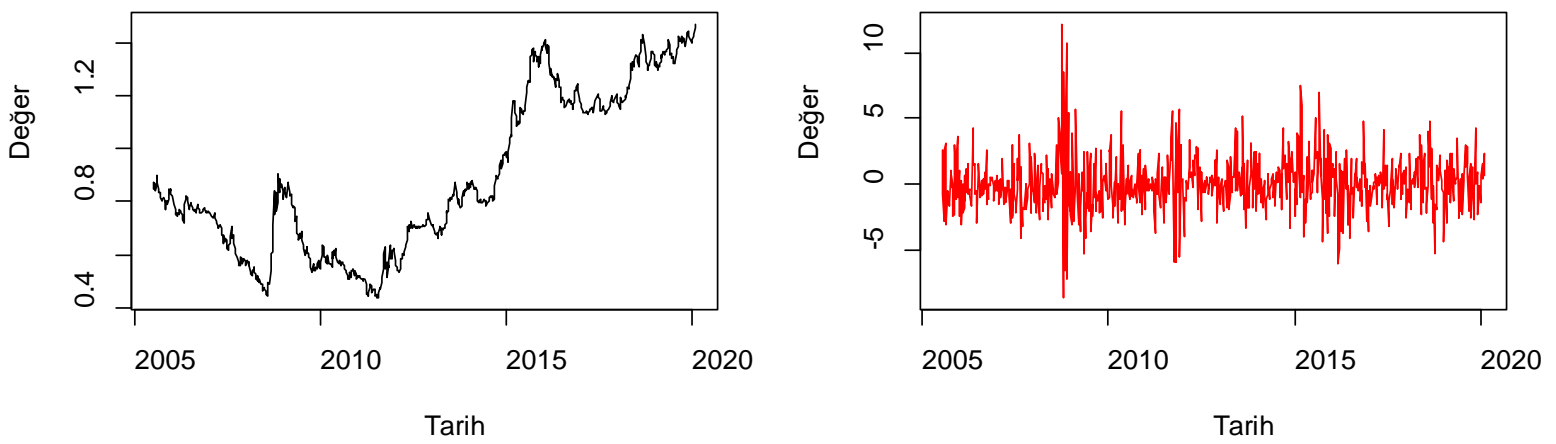

CNY Kapanış Fiyatları
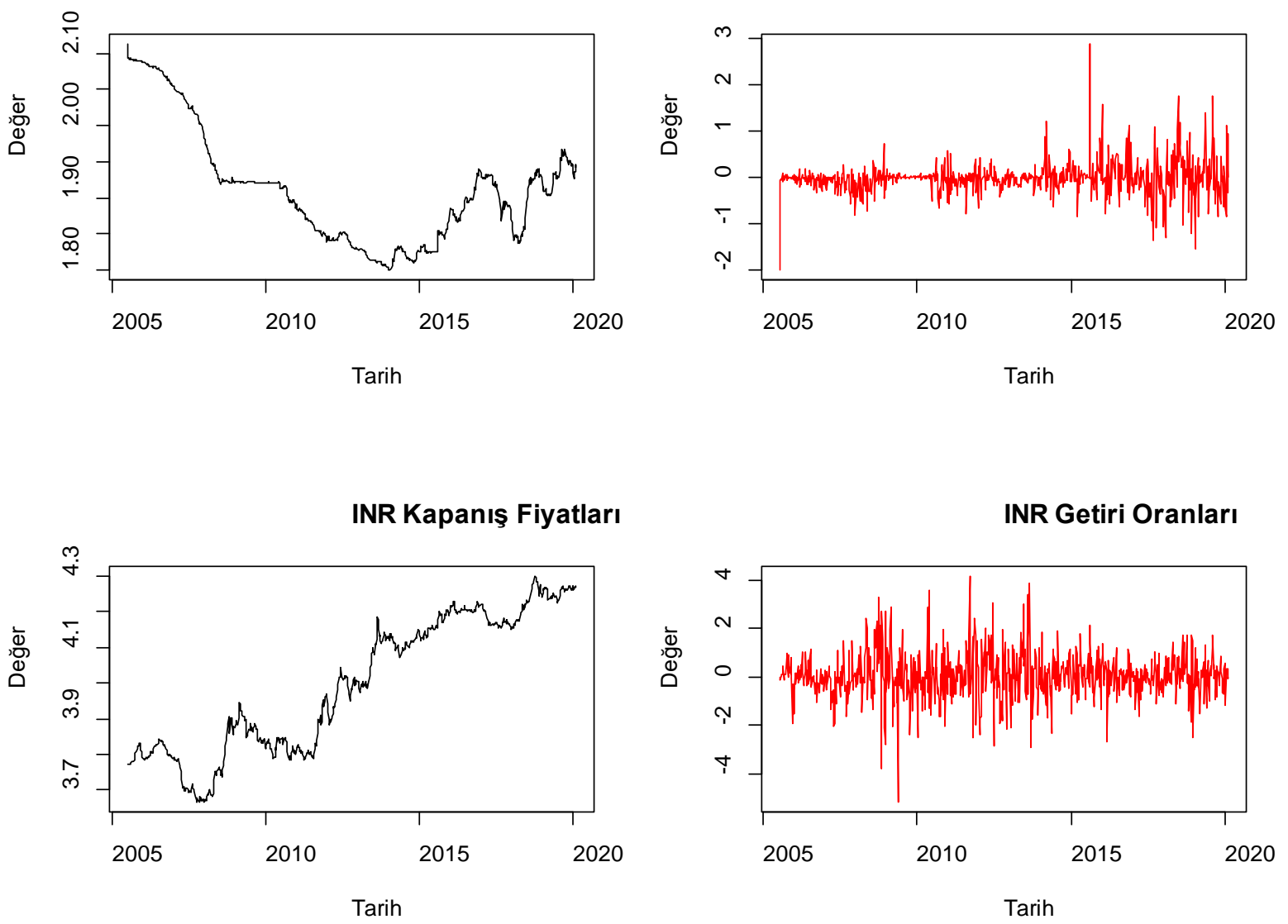
RUB Kapanış Fiyatları

RUB Getiri Oranları
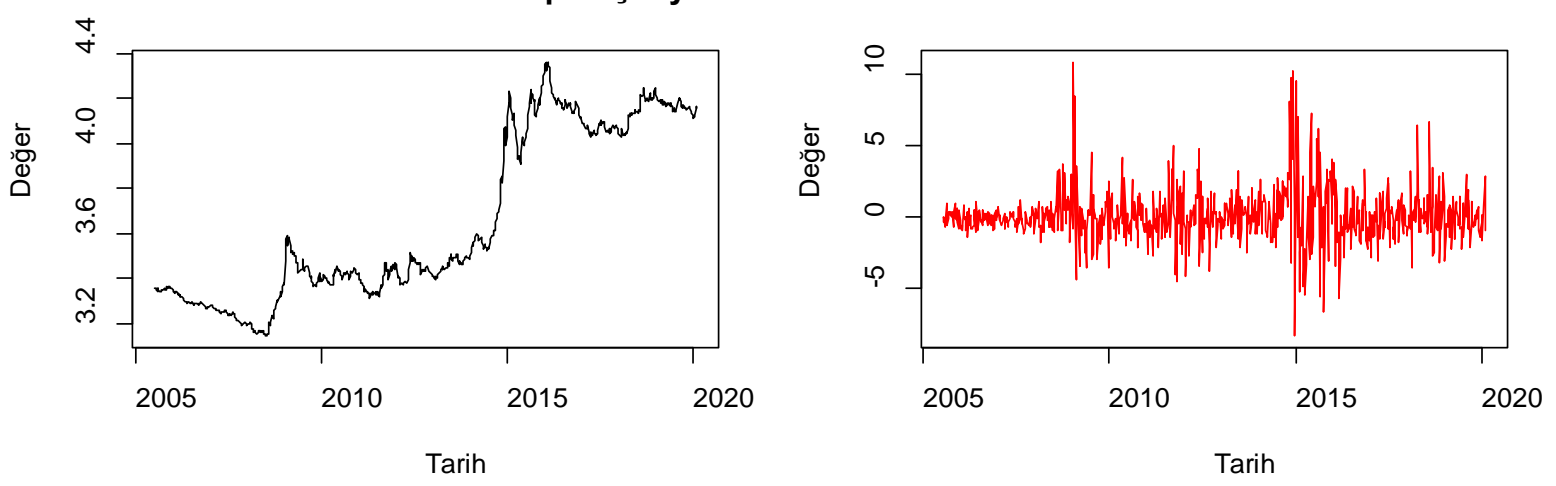

TRY Kapanış Fiyatları

TRY Getiri Oranları
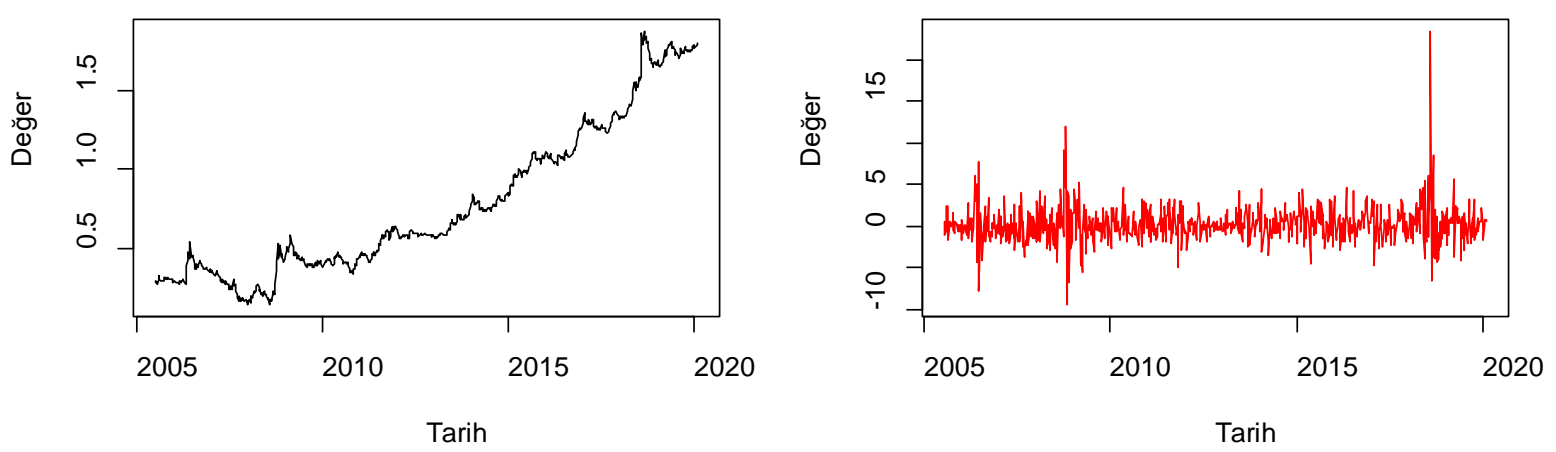

ZAR Kapanış Fiyatları

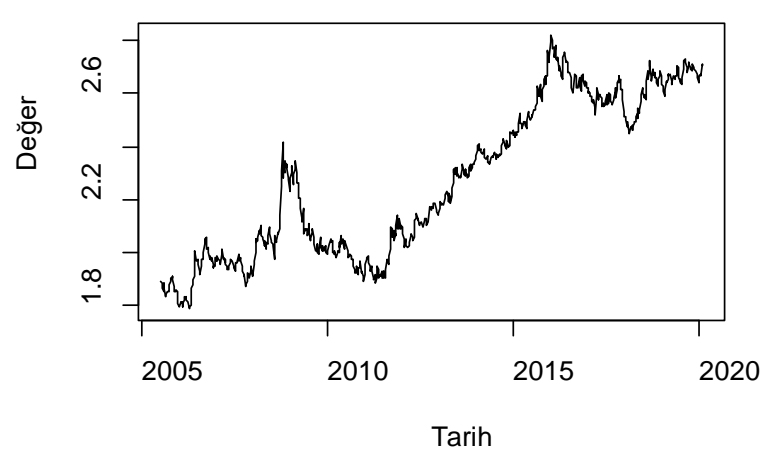

ZAR Getiri Oranları

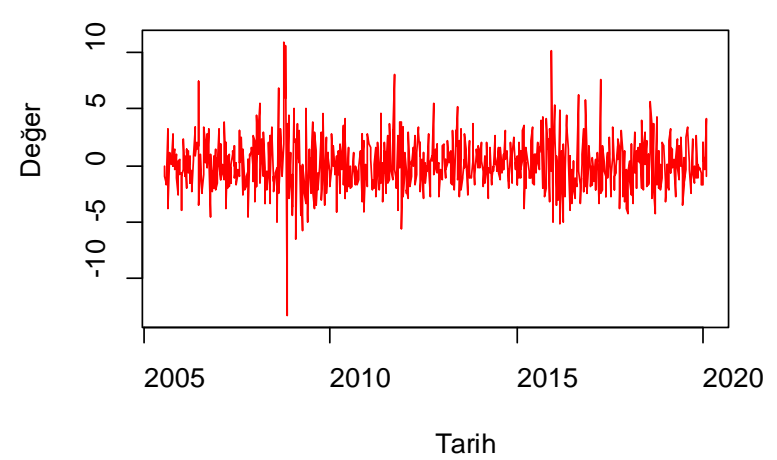

Şekil 1. Döviz Kurlarının Haftalık Kapanış Fiyatları ve Getiri Oranları Grafikleri

Şekil 1'de sol tarafta yer alan grafikler BRICS-T ülke döviz kurlarının haftalık logaritmik kapanış fiyatlarını, sağda yer alan grafikler ise haftalık getiri oranlarını göstermektedir. Analizlerin gerçekleştirileceği DL testi için veri setlerinin durağan olması gerekmektedir. Kapanış fiyatlarına ait olan grafikler döviz kurlarının durağan olmadığına, getiri oranlarına ait grafikler ise durağan olduğuna işaret etmektedir. Döviz kurlarına ait 
haftalık kapanış fiyatları ve getiri oranlarının durağanlık durumlarını daha iyi bir şekilde belirleyebilmek için söz konusu veri setlerine Said ve Dickey (1984) tarafindan geliştirilen Augmented Dickey-Fuller (ADF) ve Phillips ve Perron (1988) tarafindan geliştirilen PhillipsPerron (PP) birim kök testleri uygulanmıştır. Uygulanan ADF ve PP testleri sonuçları Tablo 1'de gösterilmektedir.

Tablo 1. ADF ve PP Birim Kök Testleri Sonuçları

\begin{tabular}{|c|c|c|c|c|c|}
\hline & & \multicolumn{2}{|c|}{ ADF Test Sonuçları } & \multicolumn{2}{c|}{ PP Test Sonuçları } \\
\hline & Veri Setleri & Sabit & Sabit ve Trendli & Sabit & Sabit ve Trendli \\
\hline \multirow{3}{*}{} & BRL & 0,037 & $-2,127$ & $-0,0801$ & $-2,187$ \\
\cline { 2 - 6 } & CNY & $-2,225$ & $-0,735$ & $-2,6427^{*}$ & $-1,225$ \\
\cline { 2 - 6 } & INR & $-0,559$ & $-2,420$ & $-0,582$ & $-2,503$ \\
\cline { 2 - 6 } & RUB & $-0,259$ & $-1,978$ & $-0,590$ & $-2,387$ \\
\cline { 2 - 6 } & TRY & 0,814 & $-1,879$ & 0,742 & $-1,953$ \\
\cline { 2 - 6 } & ZAR & $-0,950$ & $-2,664$ & $-0,912$ & $-2,571$ \\
\cline { 2 - 6 } & BRL & $-28,918^{* * *}$ & $-29,019^{* * *}$ & $-28,932^{* * *}$ & $-26,007^{* * *}$ \\
\cline { 2 - 6 } & CNY & $-10,558^{* * *}$ & $-25,265^{* * *}$ & $-26,273^{* * *}$ & $-24,868^{* * *}$ \\
\cline { 2 - 6 } & INR & $-24,756^{* * *}$ & $-24,743^{* * *}$ & $-24,882^{* * *}$ & $-26,600^{* * *}$ \\
\cline { 2 - 6 } & RUB & $-25,601^{* * *}$ & $-25,598^{* * *}$ & $-26,614^{* * *}$ & $-28,414^{* * *}$ \\
\cline { 2 - 6 } & TRY & $-28,337^{* * *}$ & $-28,415^{* * *}$ & $-28,348^{* * *}$ & $-28,647^{* * *}$ \\
\hline
\end{tabular}

Not: Her iki testin sıfir hipotezi ilgili veride birim kök olduğunu, diğer bir ifadeyle verinin durağan olmadığını belirtmektedir. ${ }^{* * *}$ ve ${ }^{*}$ işaretleri sırasıyla $1 \%$ ve $10 \%$ önem düzeyini göstermektedir.

Tablo 1'de yer alan çıktılar incelendiğinde haftalık kapanış değerlerinde birim kök olduğunu belirten sıfır hipotezinin bütün döviz kurları için kabul edildiği ve dolayısıyla haftalık kapanış fiyatlarının durağan olmadığı görülmektedir. Buna karşın getiri oranlarına ait çıktılar incelendiğinde, haftalık getiri oranlarında birim kök olduğunu belirten sıfır hipotezinin bütün döviz kurları için \%1 önem düzeyinde reddedildiği ve dolayısıyla döviz kurlarına ait haftalık getiri oranlarının durağan olduğu anlaşılmaktadır. Bu sonuçlar haftalık getiri oranları veri setlerinin DL testi için uygun olduğunu belirtmektedir. Döviz kurları haftalık getiri oranlarına ait tanımlayıcı istatistikler Tablo 2'de yer almaktadır.

Tablo 2. Tanımlayıcı İstatistikler

\begin{tabular}{|l|c|c|c|c|c|c|}
\hline & \multicolumn{7}{|c|}{ Veri Setleri } & TRY & ZAR \\
\hline & BRL & CNY & INR & RUB & 761 \\
\hline $\begin{array}{l}\text { Örneklem } \\
\text { Büyüklüğ̈̈ }\end{array}$ & 761 & 761 & 761 & 761 & 761 & 7 \\
\hline Ortalama & 0,0816 & $-0,022$ & 0,065 & 0,104 & 0,199 & 0,106 \\
\hline Minimum & $-8,642$ & $-2,019$ & $-5,160$ & $-8,270$ & $-9,447$ & $-13,334$ \\
\hline Maksimum & 12,207 & 2,890 & 4,179 & 10,827 & 23,498 & 10,976 \\
\hline Standart Sapma & 2,077 & 0,366 & 0,967 & 1,850 & 2,143 & 2,295 \\
\hline Çarpıklık & 0,653 & 0,881 & 0,032 & 1,122 & 2,000 & 0,303 \\
\hline Basıklık & 7,065 & 12,615 & 5,756 & 9,474 & 23,333 & 5,888 \\
\hline Jarque-Bera & $578,070^{* * *}$ & $3029,955^{* * *}$ & $240,965^{* * *}$ & $1488,788^{* * *}$ & $13616,400^{* * *}$ & $276,114^{* * *}$ \\
\hline ARCH & $256,333^{* * *}$ & $24,561^{* * *}$ & $57,153^{* * *}$ & $209,249^{* * *}$ & $36,526^{* * *}$ & $117,717^{* * *}$ \\
\hline
\end{tabular}

Not: Jarque-Bera testinin sıfır hipotezi ilgili verinin normal dağıldığını, ARCH testinin sıfır hipotezi ise ilgili veride koşullu değişen varyans olmadığını belirtmektedir. ${ }^{* * *}$ işareti $1 \%$ önem düzeyini göstermektedir.

Tablo 2'de yer alan bilgilere bakıldığında, en fazla ortalama getiri oranına TRY/USD kurunun sahip olduğu, en fazla oynaklığa ise 2,295 standart sapma değeri ile ZAR/USD 
kurunun sahip olduğu anlaşılmaktadır. Döviz kurlarına ait çarpıklık değeri haftalık getiri oranları veri setlerine ait dağılımın sağa çarpık olduğu, basıklık değerleri ise söz konusu dağılımın oldukça dik bir tepeye sahip olduğunu ve dolayısıyla veri setlerinin normal dağılmadığını belirtmektedir. Jarque ve Bera (1980) tarafından normallik dağılımının belirlenebilmesi için geliştirilen Jarque-Bera testi sonuçları da BRICS-T ülke döviz kurlarının normal dağgldığını belirten sıfır hipotezinin bütün kurlar için \%1 önem düzeyinde reddedildiğini, diğer bir ifadeyle döviz kurlarına ait haftalık getiri oranlarının normal dağılmadığını göstermektedir. Veri setlerinde koşullu değişen varyans etkisini tespit edilebilmesi için Engle (1982) tarafindan geliştirilen ARCH-LM testi sonuçlarına bakıldığında, haftalık getiri oranları verilerinde koşullu değişen varyansın olmadığını belirten sıfır hipotezinin bütün döviz kurları için \%1 önem düzeyinde reddedildiği, diğer bir ifadeyle haftalık getiri oranları verilerinin koşullu değişen varyans özelliği gösterdiği anlaşılmaktadır. Daha önceden de belirtildiği gibi analizlerin gerçekleştirileceği DL testi, çalışma kapsamında kullanılan döviz kurları haftalık getiri oranlarının normal dağılmama ve koşullu değişen varyans gösterme özelliklerine karşı oldukça başarılıdır.

Son olarak verilerin doğrusallık yapıları Brock vd. (1996) tarafından geliştirilen BDS testi ile incelenmiştir. Söz konusu inceleme haftalık getiri oranı serilerinin otoregresif (AR) modeli kalıntılarına uygulanmıştır. BDS testi sonucu elde edilen bulgular Tablo 3'te yer almaktadır.

Tablo 3. BDS Test Sonuçları

\begin{tabular}{lccccc}
\hline \multirow{2}{*}{ Veriler } & \multicolumn{5}{c}{$\mathbf{m}$} \\
\cline { 2 - 6 } & $\mathbf{2}$ & $\mathbf{3}$ & $\mathbf{4}$ & $\mathbf{5}$ & $\mathbf{6}$ \\
\hline BRL & $6,304^{* * *}$ & $6,515^{* * *}$ & $7,356^{* * *}$ & $8,160^{* * *}$ & $8,743^{* * *}$ \\
CNY & $10,847^{* * *}$ & $11,880^{* * *}$ & $13,464^{* * *}$ & $15,092^{* * *}$ & $17,084^{* * *}$ \\
INR & $6,330^{* * *}$ & $7,523^{* * *}$ & $8,114^{* * *}$ & $8,781^{* * *}$ & $9,229^{* * *}$ \\
RUB & $8,951^{* * *}$ & $11,270^{* * *}$ & $12,506^{* * *}$ & $14,176^{* * *}$ & $15,451^{* * *}$ \\
TRY & $6,211^{* * *}$ & $7,292^{* * *}$ & $7,627^{* * *}$ & $8,286^{* * *}$ & $9,028^{* * *}$ \\
ZAR & $4,212^{* * *}$ & $4,253^{* * *}$ & $4,250^{* * *}$ & $5,261^{* * *}$ & $5,825^{* * *}$ \\
\hline
\end{tabular}

Not: Sıfır hipotezi verilerde doğrusal yapının olduğu üzerine kurulmuştur. $\mathrm{m}$ boyut sayısını ifade etmektedir. ${ }^{* * *}$ işareti $1 \%$ önem düzeyini belirtmektedir.

Tablo 3'te yer alan bulgulara bakıldığgnda sıfır hipotezinin bütün döviz kurları için \%1 önem düzeyinde reddedildiği görülmektedir. $\mathrm{Bu}$ sonuçlar getiri oranı serilerinin tamamında doğrusal olmayan yapıların mevcut olduğunu belirtmektedir. Getiri oranı serilerinde doğrusal olmayan yapıların bulunması zaman serisi verilerinde doğrusal olmayan bağımlılıkların varlığını tespit etmek için tasarlanmış olan DL testinin çalışma kapsamındaki veri setleri için son derece ideal bir test olduğunu açık bir şekilde ortaya koymaktadır.

\section{AMPİRIK BULGULAR}

Çalışmada 104 haftalık (2 yıllık) sabit uzunluklu hareketli alt örneklem pencereleri kullanılmıştır. DL testi için olası küçük örneklem problemleri ile karşılaşmamak için alt 
örneklem uzunluğunun yeteri kadar büyük olmasına dikkat edilmiştir (Charles vd., 2012: 1618). Hareketli alt örneklem pencereleri veri seti içerisindeki önemli olaylar neticesinde oluşabilen yapısal kırılmaları doğası gereği göz önüne aldığından (Lazar vd., 2012: 344) ve zayıf formdaki piyasa etkinliğinin zaman içerisinde göstermiş olduğu değişimleri göstermesi açısından bu çalışmada tercih edilmiştir. İlk alt örneklem penceresi 17.07.2005 ile 08.07.2007 tarihleri arasındaki haftalık getiri oranlarını kapsayacak şekilde oluşturulmuştur. İlk alt örneklem penceresine DL testi uygulandıktan sonra pencere 1 hafta ileri kaydırılarak yeni alt örneklem penceresi oluşturulmuştur. $\mathrm{Bu}$ yöntemle toplam 658 alt örneklem penceresi oluşturularak her alt örneklem penceresine DL testi uygulanmış ve test çıktısını gösteren $p$ değerleri elde edilmiştir. BRICS-T döviz piyasalarının zayıf formdaki etkinliğinin zaman içerisinde göstermiş olduğu değişimleri incelemek ve söz konusu piyasaların davranışlarını açıklamada Etkin Piyasalar Hipotezi ile Adaptif Piyasalar Hipotezi'ni karşılaştırabilmek için gerçekleştirilen DL testi sonucu elde edilen $\mathrm{p}$ değerlerine ait grafikler Şekil 2'de yer almaktadir.

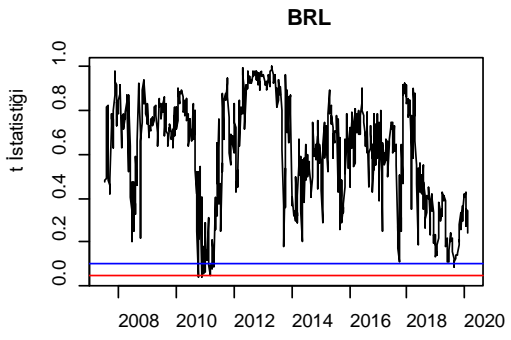

Tarih

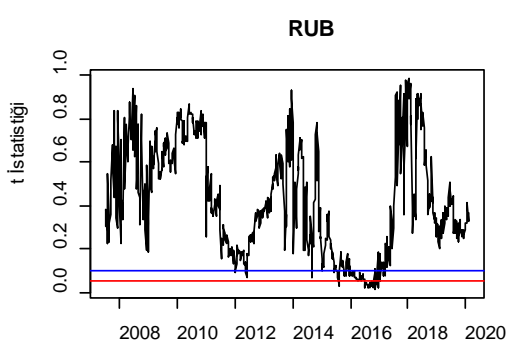

Tarih

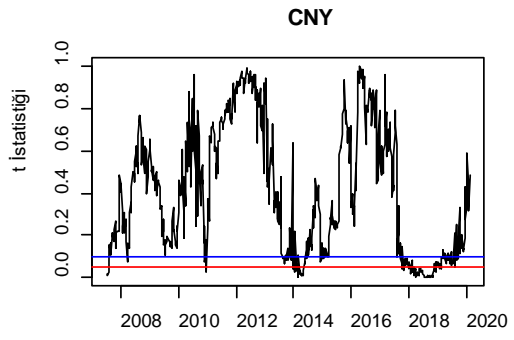

Tarih

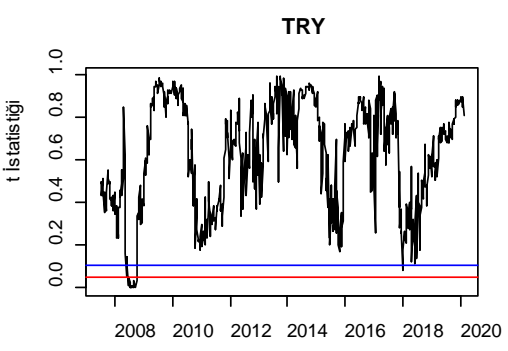

Tarih

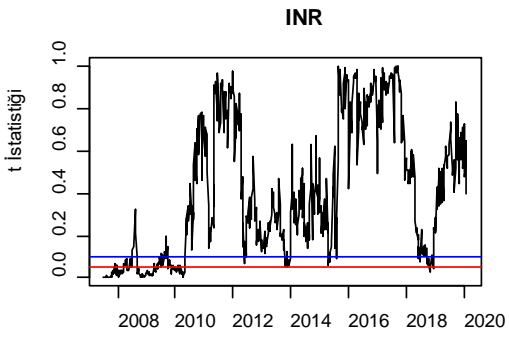

Tarih

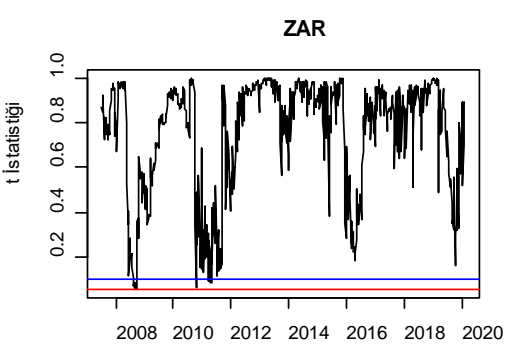

Tarih

Şekil 2. DL Testi Sonuçları

Not: Sıfir hipotezi getiri oranlarının tarihsel fiyat bilgileriyle tahmin edilemez olduğunu belirtmektedir. Yatay çizgiler sırasıyla \%5 ve \%10 önem düzeyini göstermektedir.

Şekil 2'de yer alan DL sonuçlarını gösteren grafiklerdeki yatay çizgiler $\% 5$ ve $\% 10$ önem düzeylerini, dalgalı çizgiler ise analiz sonucu ilgili tarihler için elde edilen p değerlerini göstermektedir. DL testi $\mathrm{p}$ değerlerinin, önem düzeylerini gösteren çizgilerin altında olması o tarih için sıfır hipotezinin reddedileceğini, diğer bir ifadeyle getiri oranlarının tarihsel fiyat bilgileri kullanarak tahmin edilebilir olduğunu ve söz konusu tarihte zayıf formda piyasa etkinliğinin sağlanamadığını ifade etmektedir. Önem düzeyleri çizgilerinin üstünde olan $p$ değerleri ise ilgili dönemde sıfır hipotezinin kabul edileceğini, diğer bir ifadeyle getiri oranlarının tarihsel fiyat bilgileri kullanılarak tahmin edilemeyeceğini ve zayıf formda piyasa etkinliğinin o dönem için sağlandığını belirtmektedir. Şekil 2'deki grafikler incelendiğinde döviz kurlarına ait getiri oranlarının tarihsel bilgiler kullanılarak tahmin edilebilirliğinin 
dönemsel değişimler gösterdiği, diğer bir ifadeyle BRICS-T ülke döviz piyasalarının zayıf formdaki etkinliğinin Adaptif Piyasalar Hipotezi'nin belirttiği üzere zaman içerisinde değişimler gösterdiğini açık bir şekilde göstermektedir. Bu sonuçlar BRICS-T ülke döviz piyasalarının davranışlarını açıklamada Adaptif Piyasalar Hipotezi'nin Etkin Piyasalar Hipotezi'ne göre daha başarılı olduğunu belirtmektedir. Tablo 4 döviz kurları getiri oranlarının tarihsel bilgiler kullanılarak tahmin edilebilir olduğu hafta sayılarını göstermektedir.

Tablo 4. Döviz Kurlarının Getiri Oranlarının Tahmin Edilebileceği Hafta Sayıları

\begin{tabular}{|l|c|c|}
\hline Veri Setleri & \%5 Önem Düzeyi & \%10 Önem Düzeyi \\
\hline BRL & 2 & 12 \\
\hline CNY & 72 & 134 \\
\hline INR & 98 & 159 \\
\hline RUB & 22 & 71 \\
\hline TRY & 17 & 20 \\
\hline ZAR & 0 & 10 \\
\hline
\end{tabular}

Tablo 4'te yer alan çıktılar incelendiğinde getiri oranlarının tahmin edilebildiği hafta sayısı en fazla olan döviz kurlarının CNY/USD ve INR/USD, en az olan döviz kurlarının ise $\mathrm{BRL} / \mathrm{USD}$ ve ZAR/USD olduğu görülmektedir. $\mathrm{Bu}$ sonuçlar tarihsel fiyat bilgileri kullanılarak getiri oranı tahmininde CNY/USD ve INR/USD kuru için diğer kurlara göre daha başarılı sonuçlar elde edilebileceğini ifade etmektedir. Tarihsel fiyat bilgileri ile BRL/USD ve ZAR/USD kurlarının getiri oranlarının tahmininde başarı şansı diğer kurlara göre oldukça düşüktür. Elde edilen bu sonuçlar ışığında, tarihsel fiyat hareketlerine dayanarak yatırım gerçekleştiren yatırımcıların CNY/USD ve özellikle INRUSD döviz kurlarında tasarruflarını değerlendirmeleri önerilmektedir.

\section{SONUÇ}

BRICS-T döviz piyasalarının davranışlarını açıklamada Etkin Piyasalar Hipotezi ile Adaptif Piyasalar Hipotezi'ni karşılaştırmak amacıyla gerçekleştirilen bu çalışmada 17.07.2005-09.02.2020 tarihleri arasındaki BRICS-T ülke para birimlerinin dolar karşısındaki haftalık değerleri kullanılmıştır. Çalışmada ilk olarak haftalık döviz kurlarına ait verilerin durağanlık durumları Augmented Dickey-Fuller ve Phillips-Perron birim kök testleriyle incelenmiştir. Sonraki aşamada birim kök testleri sonucunda durağan olduğu anlaşılan haftalık getiri oranlarının tanımlayıcı istatistikleri analiz edilmiş ve döviz kurlarına ait haftalık getiri oranlarının normal dağılmadığı ve koşullu değişen varyans özelliği gösterdiği belirlenmiştir. Üçüncü aşamada haftalık getiri oranlarının doğrusallık yapıları BDS testi ile incelenmiş ve bütün veri setlerinde doğrusal olmayan yapılar tespit edilmiştir. Son olarak 2 y1llık sabit uzunluklu haraketli kayan pencereler yöntemi kullanılarak doğrusal olmayan getiri oranı tahmini için geliştirilen ve çalışma kapsamındaki veri setleri gibi normal dağılmayan aynı zamanda değişen varyans özelliği gösteren veri setlerinde oldukça başarılı sonuçlar gösteren Dominguez-Lobato testi ile analizler gerçekleştirilmiştir.

Analizler sonucunda BRICS-T döviz kurlarına ait getiri oranlarının tarihsel bilgiler kullanılarak belirli dönemlerde tahmin edilebildiği, belirli dönemlerde ise tahmin edilemediği, diğer bir ifadeyle BRICS-T ülke döviz piyasalarının zayıf formdaki etkinliğinin Adaptif Piyasalar Hipotezi’nin belirttiği üzere zaman içerisinde değişimler gösterdiği belirlenmiştir. 
Bu sonuçlar BRICS-T ülke döviz piyasalarının davranışlarını açıklamada Adaptif Piyasalar Hipotezi'nin Etkin Piyasalar Hipotezi'ne göre daha başarılı olduğunu göstermektedir. Döviz kurları getiri oranlarının tarihsel bilgiler kullanılarak tahmin edilebilir olduğu hafta sayıları incelendiğinde, getiri oranlarının tahmin edilebildiği hafta sayısı en fazla olan döviz kurlarının CNY/USD ve INR/USD, en az olan döviz kurlarının ise BRL/USD ve ZAR/USD olduğu saptanmıştır. Elde edilen bu sonuçlar, tarihsel fiyat bilgileri kullanılarak getiri oranı tahmininde CNY/USD ve INR/USD kurları için diğer kurlara göre daha başarılı sonuçlar elde edilebileceğini, BRL/USD ve ZAR/USD kurlarının getiri oranlarının tahmininde ise başarısız sonuçlar elde edilebileceğini ifade etmektedir. Genel olarak çalışma kapsamında elde edilen sonuçlara bakıldığında Brezilya ve Güney Afrika döviz piyasalarının diğer BRICS-T ülke döviz piyasalarına göre daha fazla zayıf formda etkin olduğu anlaşılmaktadır. Bundan sonra gerçekleştirilecek olan çalışmalar diğer ülke döviz piyasalarının davranışlarını açıklamada Adaptif Piyasalar Hipotezi ile Etkin Piyasalar Hipotezi’nin başarısını değerlendirmek üzere gerçekleştirilebilir.

\section{KAYNAKLAR}

Aron, Janine - Ayogu, Melvin (1997), "Foreign Exchange Market Efficiency Tests in SubSaharan Africa”, Journal of African Economies, 6(3), pp. 150-192.

Beine, Michel - De Grauwe, Paul - Grimaldi, Marianna (2009), “The Impact of FX Central Bank Intervention in a Noise Trading Framework”, Journal of Banking and Finance, 33, pp. 1187-1195.

Berke, Burcu - Özcan, Burcu - Dizdarlar, Hatice Işın (2014), "Döviz Piyasasının Etkinliği: Türkiye için Bir Analiz”, Ege Akademik Bakış, 14(4), ss. 621-636.

Brock, William A. - Dechert, W. D. - Lebaron, Blake - Scheinkman, Jose Alexandre (1996), “A Test for Independence Based on a Correlation Dimension”, Econometric Review, 15, pp. 197-235.

Charles, Amélie - Darné, Olivier - Kim, Jae H. (2011), "Small Sample Properties of Alternative Tests for Martingale Difference Hypothesis”, Economics Letters, 110, pp. 151-154.

Charles, Amélie - Darné, Olivier - Kim, Jae H. (2017), "Adaptive Markets Hypothesis for Islamic Stock Indices: Evidence from Dow Jones Size and Sector-Indices", International Economics, 151, pp. 100-112.

Charles, Amélie - Darné, Olivier - Kim, Jae H. (2012), “Exchange-Rate Return Predictability and the Adaptive Markets Hypothesis: Evidence from Major Foreign Exchange Rates”, Journal of International Money and Finance, 31(6), pp. 1607-1626.

Çiçek, Macide (2014), “A Cointegration Test for Turkish Foreign Exchange Market Efficiency”, Asian Economic and Financial Review, 4(4), pp. 451-471. 
Diamandis, Panayiotis F. - Kouretas, Georgios P. - Zarangas, Leonidas (2007), “Dual Foreign Currency Markets and the Role of Expectations: Evidence from the Pacific Basin Countries”, Research in International Business and Finance, 21, pp. 238-259.

Dominguez, Kathryn M. - Frankel, Jeffrey A. (1993), “Does Foreign-Exchange Intervention Matter? The Portfolio Effect”, The American Economic Review, 83, pp. 1356-1369.

Dominguez, Manuel A. - Lobato, Ignacio N. (2003), “Testing the Martingale Difference Hypothesis”, Econometric. Reviews, 22(4), pp. 351-377.

Engle, Robert F. (1982), “Autoregressive Conditional Heteroscedasticity with Estimates of the Variance of United Kingdom Inflations”, Econometrica, 50(4), pp. 987-1007.

Ertekin, Berrin (2003), Rassal Yürüyüş Hipotezi ve Döviz Piyasalarının Etkinliğinin Araştırılması. (Yayımlanmamış Yüksek Lisans Tezi). Marmara Üniversitesi, Sosyal Bilimler Enstitüsü, İstanbul.

Fama, Eugene F. (1965), “The Behaviour of Stock Market Prices”, Journal of Business, 38, pp. 34-105.

Fama, Eugene F. (1970), "Efficient Capital Markets: A Review of Theory and Empirical Works", The Journal of Finance, 25(2), pp. 383-417.

Gupta, Rangan - Plakandaras, Vasilios (2019), "Efficiency in BRICS Currency Markets Using Long-Spans of Data: Evidence from Model-Free Tests of Directional Predictability”, Journal of Economics and Behavioral Studies, 11(1), pp. 152-165.

https://www.investing.com, Erişim Tarihi: 14.02.2020.

Jarque, Carlos M. - Bera, Anil K. (1980), "Efficient Tests for Normality, Homoscedasticity and Serial Independence of Regression Residuals”, Economics Letters, 6(3), pp. 255259.

Karadağl1, Ece Ceyda - Omay, Nazli C. (2012), “Testing Weak Form Market Efficiency of Emerging Markets: A Nonlinear Approach”, Journal of Applied Economic Sciences, 7(3), pp. 235-245.

Khuntia, Sashikanta - Pattanayak, Jamini K. (2018), “Adaptive Market Hypothesis and Evolving Predictability of Bitcoin”, Economics Letters, 167, pp. 26-28.

Khuntia, Sashikanta - Pattanayak, Jamini K. (2017), "Dynamics of Indian Foreign Exchange Market Efficiency: An Adaptive Market Hypothesis Approach”, Indian Journal of Finance, 11(9), pp. 39-52.

Korkmaz, Turhan - Başaran, Ümit - Çevik, Emrah İsmail (2010), "Yaz Saati Uygulaması Anomalisinin İMKB 100 Endeks Getirisine Etkisinin Test Edilmesi”, Ege Akademik Bakış, 10(4), ss. 1139-1153. 
Kulalı, İhsan (2016), “Etkin Piyasalar Hipotezi ve Davranışsal Finans Çatışması”, Finans ve Bankacılık Çalışmaları Dergisi, 5(2), ss. 46-57.

Kumar, Anoop S. - Kamaiah, Bandi (2016), “Efficiency, Non-Linearity and Chaos: Evidences from BRICS Foreign Exchange Markets”, Theoretical and Applied Economics, 23(1), pp. 103-118.

Kumar, Dilip (2018), “Market Efficiency in Indian Exchange Rates: Adaptive Market Hypothesis”, Theoretical Economics Letters, 8, pp. 1582-1598.

Lazar, Dorina - Todea, Alexandru - Filip, Diana (2012), “Martingale Difference Hypothesis and Financial Crisis: Empirical Evidence from European Emerging Foreign Exchange Markets”, Economic Systems, 36, pp. 338-350.

Li, Xiao-Lin - Balcilar, Mehmet - Gupta, Rangan - Chang, Tsangyao (2016), “The Causal Relationship Between Economic Policy Uncertainty and Stock Returns in China and India: Evidence from a Bootstrap Rolling Window Approach”, Emerging Markets Finance and Trade, 52(3), pp. 674-689.

Liu, Christina Y. - He, Jia (1991), “A Variance Ratio Test of Random Walks in Foreign Exchange Rate”, Journal of Finance, 46, pp. 773-785.

Lo, Andrew W. (2004), "The Adaptive Markets Hypothesis: Market Efficiency from an Evolutionary Perspective”, Journal of Portfolio Management, 30(5), pp. 15-29.

Lo, Andrew W. (2005), "Reconciling Efficient Markets With Behavioral Finance: The Adaptive Marketshypothesis”, Recent Research, 7(2), pp. 21-44.

Lo, Andrew W. (2012), “Adaptive Markets and the New World Order”, Financial Analysts Journal, 68(2), pp. 18-29.

Malkiel, Burton G. (2003), “The Efficient Market Hypothesis and Its Critics”, Journal of Economic Perspectives, 17(1), pp. 59-82.

Melvin, Michael (2004), International Money and Finance, 5th Edition, Pearson AddisonWesley, Boston.

Mohamed, M. Sheik - Banu, M. A. Shakila (2015), "Study on Weak-Form Efficiency of Foreign Exchange Markets of Developing Economies: Some India Evidence", International Journal of Management, 6(1), pp. 331-342.

Mukherjee, Shreya (2018), The Efficiency of Foreign Exchange Markets in Emerging Economies: Evidence in BRICS Countries. (Unpublished Master's Thesis). Oulu Business School, Finland.

Oh, Gabjin - Kim, Seunghwan - Eom, Cheoljun (2007), "Market Efficiency in Foreign Exchange Markets”, Physica A, 382, pp. 209-212. 
Özdemir, Arife - Vergili, Gizem - Çelik, İsmail (2018), "Döviz Piyasalarının Etkinliği Üzerinde Uzun Hafızanın Rolü: Türk Döviz Piyasasında Ampirik Bir Araştırma”, BDDK Bankacılık ve Finansal Piyasalar, 12(1), ss. 87-107.

Palma, Andreza Aparecida - Sartoris, Alexandre (2016), "Weak-Form Market Efficiency of the Brazilian Exchange Rate: Evidence from an Artificial Neural Network Model”, Latin American Business Review, 17(2), pp. 163-176.

Phillips, Peter C. B. - Perron, Pierre (1988), “Testing for a Unit Root in Time Series Regression”, Biometrika, 75(2), pp. 335-346.

Said, Said E. - Dickey, David A. (1984), “Testing for Unit Roots in Autoregressive-Moving Average Models of Unknown Order”, Biometrika, 71(3), pp. 599-607.

Samuelson, Paul A. (1965), "Proof that Properly Anticipated Prices Fluctuate Randomly", Industrial Management Review, 6, pp. 41-49.

Smith, Graham - Jefferis, Keith - Ryoo, Hyun-Jung (2002), “African Stock Markets: Multiple Variance-Ratio Tests of Random Walks”, Applied Financial Economics, 12, pp. 475484.

Yilmaz, Kamil (2003), "Martingale Property of Exchange Rates and Central Bank Intervention”, Journal of Business and Economic Statistics, 21(3), pp. 383-395. 
